\title{
Resistance to telomerase inhibition by human squamous cell carcinoma cell lines
}

\author{
BOJANA BOJOVIC and DAVID L. CROWE \\ University of Illinois Cancer Center, 801 S. Paulina Street, Room 530C, Chicago, IL 60612, USA
}

Received November 22, 2010; Accepted January 18, 2011

DOI: 10.3892/ijo.2011.935

\begin{abstract}
Telomeres are nucleoprotein structures at the ends of chromosomes that are composed of a repetitive $\mathrm{G}$ rich sequence and telomeric binding proteins. Telomeres prevent the degradation of chromosomal ends and protect against inappropriate recombination. Telomere attrition involves a tumor suppressor pathway that limits the replication of premalignant cells. The loss of telomeric DNA with each round of replication leads to growth arrest accompanied by senescence or apoptosis. Many tumor cells activate the telomerase gene to bypass senescence. Telomerase is a multisubunit ribonucleoprotein that uses an RNA template to catalyze the addition of telomeric DNA to chromosomal ends. Overexpression of the TERT subunit leads to telomere lengthening and extension of the replicative lifespan. Dominantnegative telomerase has been shown to inhibit telomerase activity in many tumor cell lines, and this is associated with telomere shortening and apoptosis. Additionally, pharmacological telomerase inhibitors have been developed which lead to progressive telomere shortening and programmed cell death In this study, we report a series of human squamous cell carcinoma cell lines that have high telomerase activity and short telomeres. Dominant-negative telomerase expression and pharmacological telomerase inhibition failed to completely inhibit enzymatic activity which was accompanied by the lack of telomere shortening. These cells continued to proliferate and demonstrated fewer responsive genes when treated with a pharmacological telomerase inhibitor. We concluded that some human squamous cell carcinoma cell lines are resistant to telomerase inhibition.
\end{abstract}

\section{Introduction}

Telomeres are nucleoprotein structures at the ends of chromosomes that are composed of a repetitive $G$ rich sequence

Correspondence to: Dr David L. Crowe, University of Illinois Cancer Center, 801 S. Paulina Street, Room 530C, Chicago, IL 60612, USA

E-mail: dlcrowe@uic.edu

Key words: telomere restriction fragment length, apoptosis, microarray, telomeric repeat amplification protocol
(TTAGGG in mammals) and telomeric binding proteins (1). These structures are dynamic and cap the ends of linear chromosomes. These caps prevent the degradation of chromosomal ends and protect against inappropriate recombination. Telomeric binding proteins allow the formation of telomeric loops which in the single-stranded overhangs normally present at telomeres invade an interior segment of duplex telomeric DNA. Telomere attrition involves a tumor suppressor pathway that limits the replication of premalignant cells (2). Human telomeres lose 50-200 bp of DNA with each population doubling (PD). Telomeres shorten faster in telomerase-deficient cells, suggesting active nucleolytic attack on chromosomal ends in addition to sequence loss due to incomplete telomere replication with each cell division (3). The loss of telomeric DNA with each round of replication leads to growth arrest accompanied by senescence or apoptosis (4). Human tumor cells bypass this proliferation block to become a clinically detectable tumor. Many tumor cells activate the telomerase gene to bypass senescence. Telomerase is a multisubunit ribonucleoprotein that uses an RNA template to catalyze the addition of telomeric DNA to chromosomal ends (5). The telomerase RNA contains a template complementary to the $\mathrm{G}$ rich telomeric repeat. The mammalian telomeric protein contains consensus reverse transcriptase motifs. Overexpression of the TERT subunit leads to telomere lengthening and extension of the replicative lifespan (6).

Mutations in the reverse transcriptase domains of the telomerase catalytic subunit have been shown to have dominantnegative activity (7). Dominant-negative telomerase (dnTERT) has been shown to inhibit telomerase activity in many tumor cell lines, and this is associated with telomere shortening and apoptosis. Additionally, pharmacological telomerase inhibitors, such as BIBR1532 have been developed which lead to progressive telomere shortening and programmed cell death (8). In this study, we report a series of human squamous cell carcinoma (SCC) cell lines that have high telomerase activity and short telomeres and are resistant to telomerase inhibition.

\section{Materials and methods}

Cell culture and stable transfection. The human SCC and breast cancer cell lines used in this study were purchased from the American Type Culture Collection and cultured in Dulbecco's modified Eagle's medium, $10 \%$ fetal bovine serum, and $40 \mu \mathrm{g} / \mathrm{ml}$ gentamicin in a humidified atmosphere 
of $5 \% \mathrm{CO}_{2}$ at $37^{\circ} \mathrm{C}$. Cultures were treated with $10 \mu \mathrm{M}$ of the pharmacological telomerase inhibitor, BIBR1532, or $0.1 \%$ DMSO vehicle for up to 400 PDs. For some experiments, cells were transfected with $2 \mu \mathrm{g}$ dnTERT or neomycin resistance plasmid using Lipofectamine according to the manufacturer's recommendations (Invitrogen). Cells were selected in $400 \mu \mathrm{g} / \mathrm{ml}$ G418 over a period of 14 days. Resistant clones were picked for expansion and characterization.

Reverse transcription polymerase chain reaction. RNA was extracted from human SCC and MDA-MB-231 dnTERT or neomycin-resistant clones using a commercially available kit (Qiagen, Valencia, CA) and was reverse transcribed using SuperScript II reverse transcriptase according to the instructions of the manufacturer (Invitrogen). cDNA was amplified using specific primers (TERT, 5'-GTGGCCTCTTCGAC GTCTTC-3' and 5'-CAAGAAATCATCCACCAAAC-3'; dnTERT, 5'-GTGGCCTCTTCGACGTCTTC-3' and 5'-CAA GAAATCAgCCACCAAAC-3') in $20 \mathrm{mM}$ Tris- $\mathrm{HCl}$ (pH 8.3), $1.5 \mathrm{mM} \mathrm{MgCl}_{2}, 63 \mathrm{mM} \mathrm{KCl}, 0.05 \%$ Tween-20, $1 \mathrm{mM}$ EGTA, $50 \mu \mathrm{M}$ of each dNTP, and 2.5 U TaqDNA polymerase (Roche Applied Science). Amplification with $\beta$-actin cDNA using primers 5'-ACAGGAAGTCCCTTGCCATC-3' and 5'-ACTGG TCTCAAGTCAGTGTACAGG-3' as the internal control was carried out by real-time PCR (iCycler, Bio-Rad) using cycle parameters $94^{\circ} \mathrm{C}$ for $25 \mathrm{sec}, 55^{\circ} \mathrm{C}$ for $1 \mathrm{~min}$, and $72^{\circ} \mathrm{C}$ for $1 \mathrm{~min}$.

Telomeric repeat amplification protocol. Cells were lysed in buffer containing $10 \mathrm{mM}$ Tris-HCl, pH 7.5, $1 \mathrm{mM} \mathrm{MgCl}$, $1 \mathrm{mM}$ EGTA, $0.1 \mathrm{mM}$ benzamidine, $5 \mathrm{mM} \beta$-mercaptoethanol, $0.5 \% 3$-[(3cholamidopropyl)dimethylammonio]-1-propanesulfonate (CHAPS) and 10\% glycerol. RNasin (1 $\mu \mathrm{l})$ was added to each sample to inhibit RNase activity. After $30 \mathrm{~min}$ incubation at room temperature, the lysates were centrifuged for $30 \mathrm{~min}$ at $12,000 \mathrm{x} \mathrm{g}$ and the supernatants were stored at $-80^{\circ} \mathrm{C}$. Protein concentrations were determined by the Bradford method using Bio-Rad protein dye reagent according to the manufacturer's recommendations. Extracts were diluted in lysis buffer and $5 \mathrm{ng}$ of protein was incubated with $100 \mathrm{ng}$ TS primer (5'-AATCCGTCGAGCAGAGTT-3') and $100 \mathrm{ng}$ ACX primer (5'-GCGCGG[CTTACC $]_{3}$ CTAACC -3'). An internal control oligonucleotide used for the quantification of telomerase activity (5'-CGTCGAGCAGAGTTAAAAGGCCG AGAAGCGAT-3') was amplified using TS primer and a return primer (5'-ATCGCTTCTCGGCCTTTT-3'). The $50 \mu \mathrm{l}$ reaction mixture also contained $50 \mu \mathrm{M}$ of each deoxynucleotide triphosphate and $5 \mu \mathrm{Ci}\left[\alpha-{ }^{32} \mathrm{P}\right]-\mathrm{dCTP}$ in $20 \mathrm{mM}$ Tris- $\mathrm{HCl}$, $\mathrm{pH} 8.3,1.5 \mathrm{mM} \mathrm{MgCl}_{2}, 63 \mathrm{mM} \mathrm{KCl}, 0.05 \%$ Tween-20, $1 \mathrm{mM}$ EGTA, and 2.5 U TaqDNA polymerase. Following a 30-min incubation at $30^{\circ} \mathrm{C}$, samples were subjected to 30 cycles of PCR at $95^{\circ} \mathrm{C}$ for $30 \mathrm{sec}, 50^{\circ} \mathrm{C}$ for $30 \mathrm{sec}$, and $72^{\circ} \mathrm{C}$ for $1 \mathrm{~min}$. The PCR products were separated on $10 \%$ nondenaturing polyacrylamide gels using $0.5 \mathrm{X}$ Tris-borate-EDTA running buffer. Gels were dried and exposed to autoradiographic film at $-80^{\circ} \mathrm{C}$ for $16 \mathrm{~h}$

Telomeric restriction fragment analysis. Genomic DNA from SCC and MDA-MB-231 cells was digested with HinfI and $R s a \mathrm{I}$ restriction enzymes at $37^{\circ} \mathrm{C}$ overnight and subjected to electrophoresis on $0.8 \%$ agarose gels. After denaturation and neutralization, DNA was blotted to nylon membranes by capillary transfer. Following blocking, membranes were hybridized with a ${ }^{32} \mathrm{P}$-end labeled 24-mer telomeric oligonucleotide probe overnight in aqueous hybridization solution at $60^{\circ} \mathrm{C}$. After three washes in $2 \mathrm{X} \mathrm{SCC}, 0.1 \% \mathrm{SDS}$ at $55^{\circ} \mathrm{C}$, blots were exposed to Kodak XAR film overnight at $-80^{\circ} \mathrm{C}$.

Apoptosis analysis. Human SCC and MDA-MB-231 cultures were fixed with $70 \%$ ethanol at $-20^{\circ} \mathrm{C}$ for $30 \mathrm{~min}$ and washed with PBS. Cells were incubated with terminal deoxynucleotidyl transferase and fluorescein-conjugated dUTP at $37^{\circ} \mathrm{C}$ for $30 \mathrm{~min}$ followed by washing in PBS. The percentage of apoptotic cells was determined by flow cytometry.

Gene expression profiling. Total RNA was extracted from BIBR1532- and DMSO-treated SCC lines and normal NHEK control cells using a commercially available kit (RNeasy, Qiagen). The integrity of the ribosomal RNA bands was confirmed by Northern gel electrophoresis. Total RNA $(10 \mu \mathrm{g})$ was converted to labeled cRNA targets. The biotinylated cRNA targets were then purified, fragmented, and hybridized to GeneChip human genome U133 expression arrays (Affymetrix, Santa Clara, CA, USA) to interrogate transcript abundance in each sample. Affymetrix GCOS software was used to generate raw gene expression scores and normalized to the relative hybridization signal from each experiment. All gene expression scores were set to a minimum value of 2 times the background determined by GCOS software in order to minimize noise associated with less robust measurements of rare transcripts. Data were analyzed by t-test with a value of $\mathrm{p}<0.005$ followed by ratio analysis (minimum 2 -fold change).

\section{Results}

To determine the effect of telomerase inhibition on human SCC lines, we expressed dnTERT in these cells by stable transfection (7). As shown in Fig. 1A, dnTERT was expressed at levels similar to those of endogenous telomerase in the human SCC lines. dnTERT expression was not detected in the neomycin-resistant SCC control clones. We also expressed dnTERT in the human breast cancer cell line, MDA-MB-231, which was shown to undergo telomere shortening and apoptosis when telomerase was inhibited (8). As shown in Fig. 1B, dnTERT expression completely inhibited telomerase activity in MDA-MB-231 clones. However, $20 \%$ of telomerase activity was still detectable in SCC clones overexpressing dnTERT when compared to the neomycin-resistant control cells. We concluded that dnTERT failed to completely inhibit telomerase activity in human SCC lines.

We examined telomere length in human SCC clones expressing dnTERT by telomeric restriction fragment analysis. As shown in Fig. 1C, SCC clones expressing dnTERT which were cultured for 100 PDs did not exhibit significant telomere shortening when compared to the neomycin-resistant control cells. Telomere length ranged from 1 to $4 \mathrm{~kb}$ in all SCC clones. In contrast, MDA-MB-231 clones expressing dnTERT demonstrated dramatic telomere shortening after 100 PDs. The range of telomere length in dnTERT-expressing MDA-MB-231 
A

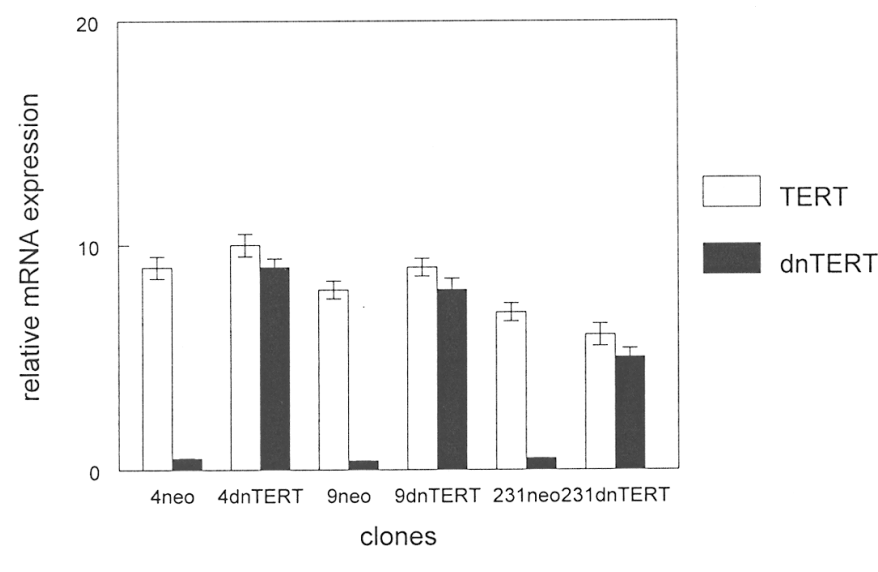

D

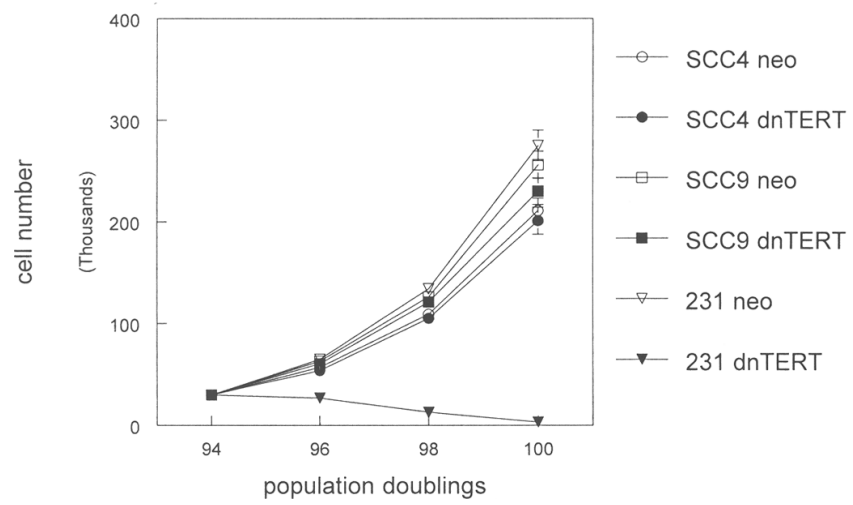

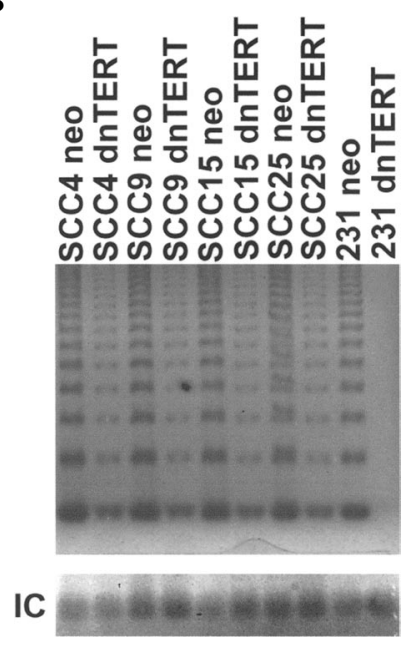

C

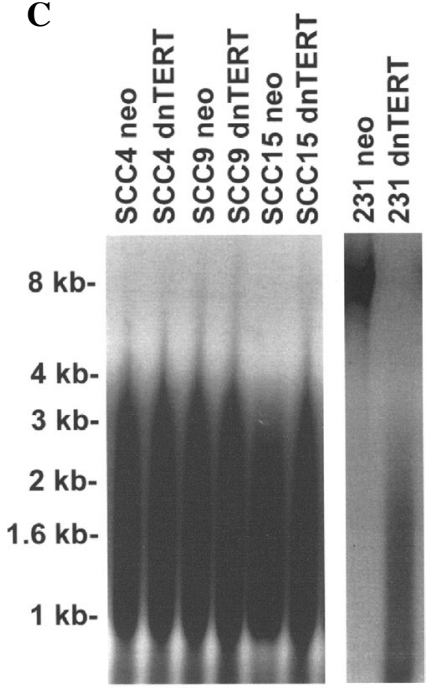

$\mathbf{E}$

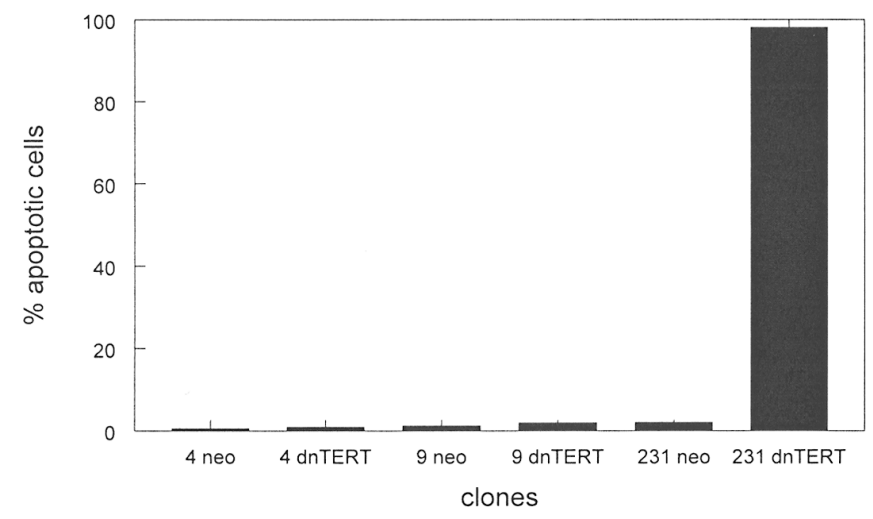

Figure 1. Human SCC lines are resistant to dnTERT expression. (A) dnTERT and TERT expression in human SCC clones is shown by quantitative reverse transcription polymerase chain reaction. Expression of dnTERT and TERT mRNAs in the human breast cancer cell line, MDA-MB-231, is shown. Expression of dnTERT and TERT mRNAs is shown in neomycin-resistant control clones. Error bars indicate SEM of three independent experiments. (B) dnTERT failed to completely inhibit telomerase activity in human SCC lines. Telomerase activity in human dnTERT and neomycin-resistant control SCC clones is shown by telomeric repeat amplification protocol. Telomerase activity in dnTERT and neomycin-resistant MDA-MB-231 clones is shown. Levels of the internal amplification control (IC) are shown. Representative gels of three independent experiments are shown. (C) Lack of telomere shortening in human SCC clones expressing dnTERT. Telomere length in dnTERT or neomycin-resistant SCC clones is shown by telomeric restriction fragment length analysis. Telomere length in dnTERT or neomycin-resistant MDA-MB-231 control clones is shown. Representative gels of three independent experiments are shown. (D) Proliferation of human SCC lines is not affected by dnTERT expression. dnTERT and neomycin-resistant SCC clones were counted at 2 day intervals for 100 PDs. Proliferation of dnTERT and neomycin-resistant MDA-MB-231 control clones is shown. Error bars indicate SEM of three independent experiments. (E) Human SCC lines expressing dnTERT fail to undergo apoptosis. The percentage of apoptotic cells in dnTERT and neomycin-resistant SCC clones was determined by TUNEL assay. The percentage of apoptotic cells in dnTERT and neomycin-resistant MDA-MB-231 control clones is shown. Error bars indicate SEM of three independent experiments.

clones was $<1$ to $2.5 \mathrm{~kb}$ compared to $8 \mathrm{~kb}$ in the neomycinresistant control cells. We concluded that dnTERT did not produce telomere shortening in human SCC lines.

We examined proliferation in human SCC lines expressing dnTERT. As shown in Fig. 1D, we did not detect significant differences in proliferation rates between the dnTERT and neomycin-resistant SCC clones. dnTERT SCC clones were cultured for 400 PDs without detectable decreases in proliferation. In contrast, MDA-MB-231 clones expressing dnTERT had ceased proliferation by 100 PDs while neomycin-resistant MDA-MB-231 cells were highly proliferative. The loss of proliferation in dnTERT-expressing MDA-MB-231 clones was associated with the dramatic induction of apoptosis as determined by TUNEL assay and cell detachment from the culture flasks (Fig. 1E). In contrast, no increase in apoptosis was observed in the dnTERT-expressing SCC clones. We concluded that dnTERT had no effect on cellular proliferation or apoptosis in human SCC lines.

To replicate these results using a different means of telomerase inhibition, we treated human SCC lines and MDA-MB-231 cells with $10 \mu \mathrm{M}$ BIBR1532. As shown in Fig. 2A, BIBR1532 treatment completely inhibited telomerase activity in MDA-MB-231 cells. In contrast, 10-20\% of telomerase activity was detected in human SCC lines following BIBR1532 treatment. We concluded that BIBR1532 treatment failed to completely inhibit telomerase activity in human SCC lines.

We examined telomere length in human SCC lines treated with BIBR 1532 by telomeric restriction fragment analysis. As 
A

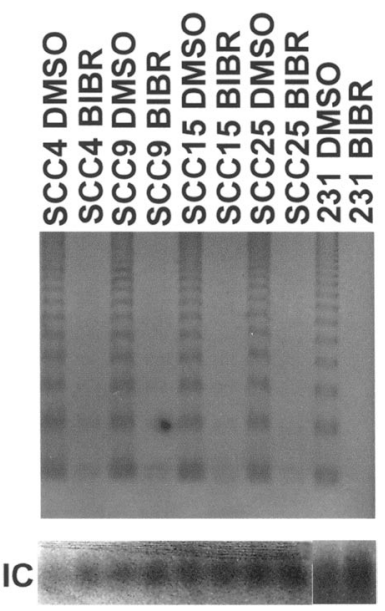

C

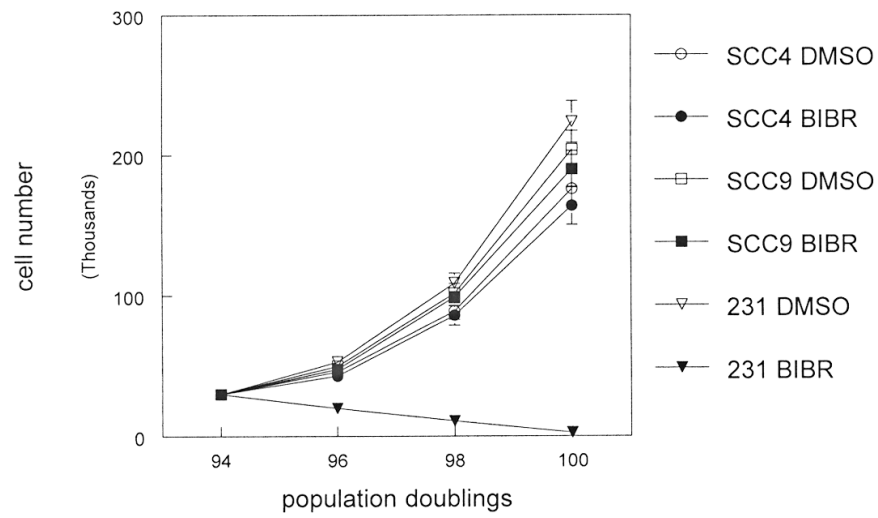

B

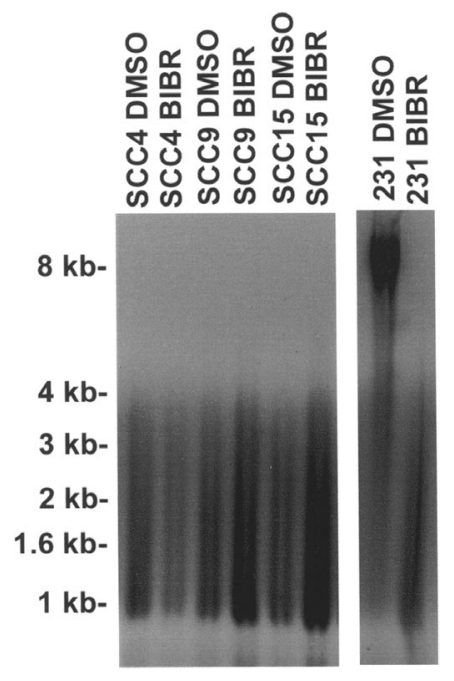

D

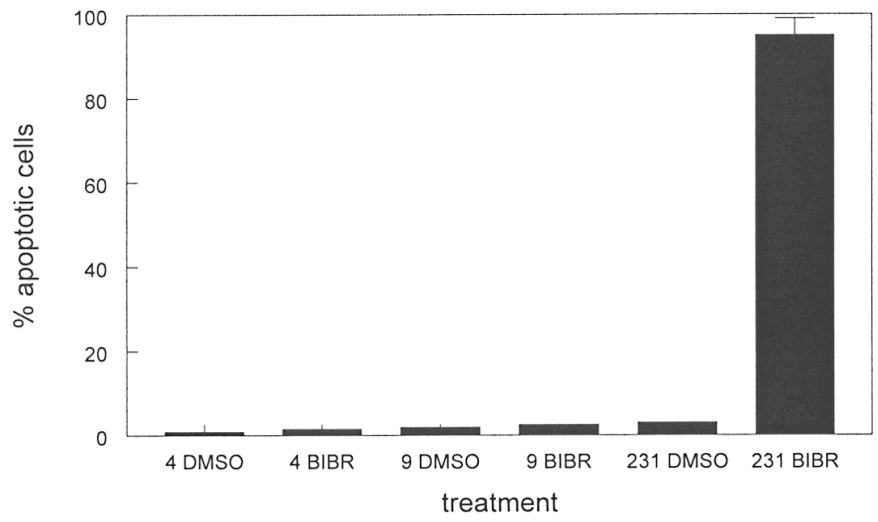

Figure 2. Human SCC lines are resistant to the pharmacological inhibition of telomerase. (A) Telomerase activity in human SCC lines treated with the telomerase inhibitor, BIBR1532, or DMSO vehicle is shown by telomeric repeat amplification protocol. Telomerase activity in BIBR1532 and DMSO MDA-MB-231 cells is shown. Levels of the internal amplification control (IC) are shown. Representative gels of three independent experiments are shown. (B) Lack of telomere shortening in BIBR1532-treated human SCC cells. Telomere length in SCC cells is shown by telomeric restriction fragment length analysis. Telomere length in BIBR1532-treated MDA-MB-231 control cells is shown. Control cultures were treated with DMSO vehicle. Representative gels of three independent experiments are shown. (C) Proliferation of human SCC lines is not affected by BIBR1532 treatment. SCC cells treated with BIBR1532 or DMSO vehicle were counted at 2 day intervals for 100 PDs. Proliferation of BIBR1532 or vehicle treated MDA-MB-231 control cells is shown. Error bars indicate SEM of three independent experiments. (D) Human SCC lines treated with BIBR1532 failed to undergo apoptosis. The percentage of apoptotic cells in BIBR1532- or DMSO-treated SCC cells was determined by TUNEL assay. The percentage of apoptotic cells in BIBR1532- or DMSO-treated MDA-MB-231 control cells is shown. Error bars indicate SEM of three independent experiments.

shown in Fig. 2B, SCC lines treated with BIBR1532 and cultured for 100 PDs did not exhibit significant telomere shortening when compared to the control cells treated with $0.1 \%$ DMSO vehicle. Telomere length ranged from 1 to $4 \mathrm{~kb}$ in all SCC clones. In contrast, MDA-MB-231 cells treated with BIBR1532 demonstrated dramatic telomere shortening after 100 PDs. The range of telomere length in the MDA-MB-231 cells treated with BIBR1532 was $<1$ to $2.5 \mathrm{~kb}$ compared to $8 \mathrm{~kb}$ in the vehicle-treated control cells. We concluded that BIBR1532 treatment did not produce telomere shortening in human SCC lines.

We examined proliferation in human SCC lines treated with BIBR1532. As shown in Fig. 2C, we did not detect significant differences in proliferation rates between the BIBR1532- and vehicle-treated SCC lines. SCC lines treated with BIBR1532 were cultured for 400 PDs without detectable decreases in proliferation. In contrast, MDA-MB-231 cells treated with BIBR1532 had ceased proliferation by 100 PDs while the vehicle-treated MDA-MB-231 cells were highly proliferative. The loss of proliferation in BIBR1532 MDA-MB231 cells was associated with the dramatic induction of apoptosis as determined by TUNEL assay and cell detachment from the culture flasks (Fig. 2D). In contrast, no increase in apoptosis was observed in the BIBR1532-treated SCC clones. We concluded that BIBR1532 had no effect on cellular proliferation or apoptosis in human SCC lines.

To compare anti-telomerase resistance in SCC lines to their normal cellular counterparts, we performed gene expression profiling on SCC25 cells and the normal stratified squamous epithelial strain NHEK treated with BIBR1532. The expression of 499 genes in NHEK cells was altered by BIBR1532, compared to 140 differentially expressed genes in the SCC25 line (Tables I and II). BIBR 1532 treatment regulated different sets of genes in both the NHEK and SCC25 cells. In the NHEK cells, upregulated genes included thymidine kinase 2 (9.8-fold), connective tissue growth factor 
Table I. Gene expression changes between NHEK vehicle- and BIBR1532-treated cells (499 differentially expressed genes).

\begin{tabular}{|c|c|c|c|}
\hline Accession & Gene symbol & Gene name & Fold change \\
\hline X07695 & KRT4 & Keratin 4 & 78.8 \\
\hline NM_002888 & RARRES1 & Retinoic acid receptor responder 1 & 64.4 \\
\hline X02189 & ADA & Adenosine deaminase & 39.3 \\
\hline AF144103 & CXCL14 & Chemokine (C-X-C motif) ligand 14 & 25.0 \\
\hline BG532690 & ITGA4 & Integrin, $\alpha 4$ & 21.8 \\
\hline NM_000782 & CYP24A1 & Cytochrome p450, family 24 , subfamily A, polypeptide 1 & 14.7 \\
\hline NM_000930 & PLAT1 & Plasminogen activator, tissue & 13.9 \\
\hline AW117498 & FOXO1A & Forkhead box 01A (rhabdomyosarcoma) & 13.5 \\
\hline AF119835 & KITLG & KIT ligand & 13.0 \\
\hline AA524412 & TK2 & Thymidine kinase 2 , mitochondrial & 9.8 \\
\hline M92934 & CTGF & Connective tissue growth factor & 9.7 \\
\hline NM_004878 & PTGES & Prostaglandin E synthetase & 9.5 \\
\hline AL050262 & TLR1 & Toll-like receptor 1 & 9.0 \\
\hline NM_002876 & RAD51C & RAD51 homolog C (S. cerevisiae) & 8.3 \\
\hline AF012536 & TNFRSF10C & Tumor necrosis factor receptor superfamily, member 10c & 8.2 \\
\hline BC020765 & SERPINE1 & Serine (or cysteine) proteinase inhibitor, clade E, member 1 & 7.9 \\
\hline NM_005375 & MYB & v-Myb myeloblastosis viral oncogene homolog (avian) & 7.2 \\
\hline AI758962 & EPHA4 & EPH receptor A4 & 7.1 \\
\hline BE219979 & IL20RA & Interleukin 20 receptor, $\alpha$ & 6.9 \\
\hline AF118886 & VAV3 & Vav 3 oncogene & 6.8 \\
\hline BC005008 & CEACAM6 & Carcinoembryonic antigen-related cell adhesion molecule 6 & 6.6 \\
\hline ВC004877 & UNG2 & Uracil DNA glycosylase 2 & 6.1 \\
\hline NM_015400 & SMAD3 & SMAD, mothers against DPP homolog 3 (Drosophila) & 6.0 \\
\hline AA742293 & CREBBP & CREB-binding protein (Rubinstein-Taybi syndrome) & 5.9 \\
\hline AF308602 & NOTCH1 & Notch homolog 1, translocation-associated (Drosophila) & 5.9 \\
\hline BF971923 & MAP3K3 & Mitogen-activated protein kinase kinase kinase 3 & 5.3 \\
\hline AF072872 & FZD1 & Frizzled homolog 1 (Drosophila) & 5.3 \\
\hline AY009400 & WNT10A & Wingless type MMTV integration site family, member 10A & 5.1 \\
\hline U57001 & EFNB3 & Ephrin b3 & -5.2 \\
\hline NM_021724 & THRA & Thyroid hormone receptor, $\alpha$ & -5.4 \\
\hline NM_003593 & FOXN1 & Forkhead box N1 & -5.4 \\
\hline NM004994 & MMP9 & Matrix metalloproteinase 9 & -5.5 \\
\hline BF196457 & DSC2 & Desmocollin 2 & -5.7 \\
\hline AL575177 & NOG & Noggin & -5.8 \\
\hline AK021881 & HIF3A & Hypoxia inducible factor $3, \alpha$ subunit & -5.8 \\
\hline NM_002923 & RGS2 & Regulator of G protein signaling 2,24 kDa & -5.8 \\
\hline U04897 & RORA & RAR related orphan receptor $A$ & -5.8 \\
\hline AK026546 & CXCL5 & Chemokine (C-X-C motif) ligand 5 & -5.9 \\
\hline AJ276395 & FN1 & Fibronectin 1 & -6.0 \\
\hline ВC032003 & SPINK6 & Serine protease inhibitor, Kazal type 6 & -6.3 \\
\hline NM_002425 & MMP10 & Matrix metalloproteinase 10 (stromelysin 2) & -6.5 \\
\hline AW007532 & IGFBP5 & Insulin-like growth factor binding protein 5 & -6.9 \\
\hline BF110534 & RASGEF1B & RasGEF domain family, member 1B & -7.1 \\
\hline $\mathrm{H} 23551$ & PAK3 & p21 (CDKN1A) activated kinase 3 & -7.1 \\
\hline N71063 & ADAMTS6 & A disintegrin-like and metalloprotease, thrombospondin motif 6 & -8.3 \\
\hline U64094 & IL1R2 & Interleukin 1 receptor, type II & -8.5 \\
\hline NM_000359 & TGM1 & Transglutaminase 1 & -8.8 \\
\hline BE671224 & STK11 & Serine/threonine kinase 11 (Peutz-Jeghers syndrome) & -8.9 \\
\hline AF277897 & EGFR & Epidermal growth factor receptor & -10.6 \\
\hline AV682252 & GLIPR1 & GLI pathogenesis-related 1 (glioma) & -12.2 \\
\hline AB049591 & CNFN & Cornifelin & -21.2 \\
\hline NM_000640 & IL13RA2 & Interleukin 13 receptor, $\alpha 2$ & -43.5 \\
\hline
\end{tabular}


Table II. Gene expression changes between SCC25 vehicle- and BIBR1532-treated cells (140 differentially expressed genes).

\begin{tabular}{|c|c|c|c|}
\hline Accession & Gene symbol & Gene name & Fold change \\
\hline BC002710 & KLK10 & Kallikrein 10 & 18.0 \\
\hline NM_005052 & RAC3 & Ras-related $\mathrm{C} 3$ botulinum toxin substrate 3 & 8.8 \\
\hline AU149305 & MMP14 & Matrix metalloproteinase 14 (membrane-inserted) & 8.6 \\
\hline AF082185 & TRAF4 & TNF receptor-associated factor 4 & 8.2 \\
\hline NM_024302 & MMP28 & Matrix metalloproteinase 28 & 7.5 \\
\hline NM_000499 & CYP1A1 & Cytochrome P450, family 1, subfamily A, polypeptide 1 & 6.9 \\
\hline AI800895 & MAP4K3 & Mitogen-activated protein kinase kinase kinase kinase 3 & 6.4 \\
\hline NM_001552 & IGFBP4 & Insulin-like growth factor binding protein 4 & 6.1 \\
\hline NM_002428 & MMP15 & Matrix metalloproteinase 15 (membrane-inserted) & 6.1 \\
\hline BE965869 & RAB40C & RAB40C, member RAS oncogene family & 6.0 \\
\hline NM_002899 & RBP1 & Retinol-binding protein 1 , cellular & 5.5 \\
\hline AW192876 & CSNK1E & Casein kinase $1, \varepsilon$ & 5.4 \\
\hline AA496799 & BCAR3 & Breast cancer anti-estrogen resistance 3 & 5.4 \\
\hline AK098058 & MAPK12 & Mitogen-activated protein kinase 12 & 5.3 \\
\hline AW117498 & FOXO1A & Forkhead box O1A (rhabdomyosarcoma) & 5.3 \\
\hline NM_021114 & SPINK2 & Serine protease inhibitor, Kazal type 2 (acrosin-trypsin inhibitor) & 5.0 \\
\hline BG281679 & TYMS & Thymidylate synthetase & 5.0 \\
\hline NM_017781 & CYP2W1 & Cytochrome P450, family 2, subfamily W, polypeptide 1 & -5.1 \\
\hline NM_139057 & ADAMTS17 & A disintegrin and metalloprotease, thrombospondin motif, 17 & -5.1 \\
\hline AW341182 & DLL3 & $\delta$ like 3 (Drosophila) & -5.2 \\
\hline BE671224 & STK11 & Serine/threonine kinase 11 (Peutz-Jeghers syndrome) & 5.3 \\
\hline BE311922 & $\mathrm{CDC} 42 \mathrm{BPB}$ & CDC42 binding protein kinase $\beta$ (DMPK like) & -5.4 \\
\hline ВC004490 & FOS & v-Fos FBJ murine osteosarcoma viral oncogene homolog & -5.5 \\
\hline BF476613 & MUC & Mucin & -5.6 \\
\hline AF095784 & GPR51 & G protein-coupled receptor 51 & -5.6 \\
\hline AI912696 & MAGEE1 & Melanoma antigen family E, 1 & -5.8 \\
\hline AF085825 & POLA & Polymerase (DNA directed), $\alpha$ & -5.9 \\
\hline NM_004573 & PLCB2 & Phospholipase $\mathrm{C}, \beta 2$ & -5.9 \\
\hline AA016035 & TUBGCP2 & Tubulin, $\gamma$ complex-associated protein 2 & -6.0 \\
\hline U47924 & CD4 & CD4 antigen & -6.3 \\
\hline N25325 & CALM1 & Calmodulin 1 (phosphorylase kinase, $\delta$ ) & -6.5 \\
\hline AI459194 & EGR1 & Early growth response 1 & -6.5 \\
\hline ВC002646 & JUN & v-Jun sarcoma virus 17 oncogene homolog (avian) & -7.9 \\
\hline
\end{tabular}

(9.7-fold), RAD51 homolog C (8.3-fold), vav3 oncogene (6.8fold), SMAD3, (6-fold), CBP (5.9-fold), frizzled homolog 1 (5.3-fold), and Wnt10a (5.1-fold). Downregulated genes included thyroid hormone receptor $\alpha(-5.4$-fold), desmocollin 2 (-5.7 fold), transglutaminase 1 (-8.8-fold), epidermal growth factor receptor (-10.6-fold), and cornifelin (-21.2-fold). In SCC25 cells, upregulated genes included Rac3 (8.8-fold), cytochrome P450 family 1 (6.9-fold), casein kinase $1 \varepsilon$ (5.4fold), breast cancer anti-estrogen resistance 3 (5.4-fold) and thymidylate synthetase (5-fold). Downregulated genes included $\delta$-like 3 (-5.2-fold), serine/threonine kinase 11 (-5.3fold), c-fos (-5.5-fold), DNA polymerase $\alpha$ (-5.9 fold), phospholipase C $\beta 2$ (-5.9-fold), and c-jun (-7.9-fold). These results indicate that $\mathrm{BIBR} 1532$ does not regulate the same gene sets in NHEK and SCC25 cells.

\section{Discussion}

Our results indicate that human SCC lines are resistant to telomerase inhibition by dnTERT expression and pharmacological treatment. Both methodologies failed to completely inhibit telomerase activity while the control human breast cancer cell line, MDA-MB-231, was completely inhibited. Telomere length was not shortened in SCC lines by dnTERT or pharmacological inhibition, proliferation was not decreased, and apoptosis was not increased in these cells. Previous studies have demonstrated that telomerase activity in cancer cells can be inhibited by a number of reagents, such as antisense molecules coupled to peptides to increase cellular uptake (9-11). The telomerase inhibitor, telomestatin, was effective in inhibiting activity, inducing telomere shortening, 
growth inhibition and apoptosis (12). G quadruplex ligands have been shown to stabilize telomere structure and inhibit access by telomerase (13). The TERT promoter has been used to transduce antisense ornithine decarboxylase RNA into cells via adenoviral vectors, inhibiting cancer cell proliferation (14). Newer drugs such as coumarin derivatives have been shown to inhibit telomerase in gastric cancer cells (15). Previously described telomerase inhibitors, such as GRN163L have anti-cancer effects without effects on normal stem cell populations, which suggests that this drug may be useful in cancer therapy without resulting in stem cell depletion (16-19).

The DNA damage response following telomerase inhibition is substantially different than that induced by cytotoxic chemotherapy. Pharmacological inhibition of telomerase does not induce cell cycle inhibition and differentiation in SCC lines. Our study indicates that long-term telomerase inhibition is not effective in human SCC lines, suggesting that resistance to this therapy is a common feature of these cells. Future studies are required to determine the mechanisms of this resistance in order to increase the effectiveness of telomerase inhibition in cancer cells.

\section{Acknowledgments}

We thank Drs Murray Robinson and Klaus Damm for the reagents. This study was supported by National Institutes of Health grant DE14512.

\section{References}

1. Bailey SM, Cornforth MN, Kurimasa A, Chen DJ and Goodwin EH: Strand specific postreplicative processing of mammalian telomeres. Science 293: 2462-2465, 2001.

2. Wang RC, Smogorzewska A and de Lange T: Homologous recombination generates $\mathrm{T}$ loop sized deletions at human telomeres. Cell 119: 355-368, 2004.

3. Fitzgerald MS, Riha K, Gao F, Ren S, McKnight TD and Shippen DE: Disruption of the telomerase catalytic subunit gene from Arabidopsis inactivates telomerase and leads to a slow loss of telomeric DNA. Proc Natl Acad Sci USA 96: 14813-14818, 1999.

4. Karlseder J, Smogorzewska A and de Lange T: Senescence induced by altered telomere state, not telomere loss. Science 295: 2446-2449, 2002.

5. Harrington L, Zhou W, McPhail T, Oulton R, Yeung DSK, Mar V, Bass MB and Robinson MO: Human telomerase contains evolutionarily conserved catalytic and structural subunits. Genes Dev 11: 3109-3115, 1997.
6. Bodnar AG, Ouellette M, Frolkis M, Holt SE, Chiu CP, Morin GB, Harley CB, Shay JW, Lichtsteiner S and Wright WE: Extension of lifespan by introduction of telomerase into normal human cells. Science 279: 349-352, 1998.

7. Zhang X, Mar V, Zhou W, Harrington L and Robinson MO: Telomere shortening and apoptosis in telomerase inhibited human tumor cells. Genes Dev 13: 2388-2399, 1999.

8. Damm K, Hemmann U, Garin-Chesa P, et al: A highly selective telomerase inhibitor limiting human cancer cell proliferation. EMBO J 20: 6958-6968, 2001.

9. Park JG: Effective inhibition of cancer cell growth by a novel tripartite transfection complex containing ribbon antisense molecules to hTR. Cancer Res Treat 36: 308-314, 2004.

10. Diala I, Murao S and Fujii M: Antisense inhibition of human telomerase by phosphorothioate oligonucleotide peptide conjugates. Nucleic Acids Symp Ser 52: 679-680, 2008.

11. Gryaznov SM: Oligonucleotide n3'-> p5' phosphoramidates and thio-phosphoramidates as potential therapeutic agents. Chem Biodivers 7: 477-493, 2010.

12. Long S, Argyle DJ, Gault EA and Nasir L: Inhibition of telomerase in canine cancer cells following telomestatin treatment. Vet Comp Oncol 5: 99-107, 2007.

13. Chen Z, Zheng KW, Hao YH and Tan Z: Reduced or diminished stabilization of the telomere $G$ quadruplex and inhibition of telomerase by small chemical ligands under molecular crowding conditions. J Am Chem Soc 131: 10430-10438, 2009.

14. Wang W, Jin B, Li W, Xu CX, Cui FA, Liu B, Yan YF, Liu XX and Wang XL: Targeted antitumor effect induced by hTERT promoter mediated ODC antisense adenovirus. Mol Biol Rep 37: 3239-3247, 2010

15. Liu XH, Liu HF, Chen J, Yang Y, Song BA, Bai LS, Liu JX, Zhu HL and Qi XB: Synthesis and molecular docking study of novel coumarin derivatives containing 4,5-dihydropyrazole moiety as potential antitumor agents. Bioorg Med Chem Lett 20: 5705-5708, 2010

16. Tokcaer-Keskin Z, Dikmen ZG, Ayaloglu-Butun F, Gultekin S, Gryaznov SM and Akcali KC: The effect of telomerase template antagonist GRN163L on bone marrow derived rat mesenchymal stem cells is reversible and associated with altered expression of cyclin D1, cdk4, and cdk6. Stem Cell Rev 6: 224-233, 2010.

17. Brennan SK, Wang Q, Tressler R, Harley C, Go N, Basset E, Huff CA, Jones RJ and Matsui W: Telomerase inhibition targets clonogenic multiple myeloma cells through telomere length dependent and independent mechanisms. PLoS One 5: e12487, 2010.

18. Marian CO, Cho SK, McEllin BM, Maher EA, Hatanpaa KJ, Madden CJ, Mickey BE, Wright WE, Shay JW and Bachoo RM: The telomerase antagonist imetelstat efficiently targeted glioblastoma tumor initiating cells leading to decreased proliferation and tumor growth. Clin Cancer Res 16: 154-163, 2010.

19. Marian CO, Wright WE and Shay JW: The effects of telomerase inhibition on prostate tumor initiating cells. Int J Cancer 127 321-331, 2010. 